Epidemiology

\title{
Normative values of handgrip strength in adolescents according to chronological age and sexual maturation
}

\author{
Mateus Augusto Bim ${ }^{1}$ (D), André de Araújo Pinto ${ }^{1}$ (D), Diego Augusto Santos Silva ${ }^{2}$ (D), \\ Anna Mestriner Rodrigues ${ }^{1}$ D, Andreia Pelegrini ${ }^{1}$ \\ ${ }^{1}$ Universidade do Estado de Santa Catarina, Florianópolis, SC, Brasil; ${ }^{2}$ Universidade Federal de \\ Santa Catarina, Florianópolis, SC, Brasil.
}

Associate Editor: Danilo Rodrigues Pereira da Silva, Universidade Federal de Sergipe, São

Cristóvão, SE, Brasil.

\begin{abstract}
Aim: Handgrip strength is considered an important health indicator. It is extremely important to establish normative values so that the handgrip strength is correctly interpreted in adolescents. The present study aims to establish normative values of handgrip strength (HGS) for adolescents, according to chronological age and sexual maturation. Methods: Data from three large projects carried out in Florianopolis and São José, Santa Catarina were used, corresponding to a sample of 2,637 adolescents aged 14 to 19 years old of both sexes (1,428 girls). The HGS of the right and left hands was measured by a manual dynamometer, and total HGS being defined by the sum of the left hand and the right-hand strength. Sexual maturation was determined by the development of pubic hair. The percentiles 3, 10, 15, 25, 50, 75, 85, 90, and 97 were calculated for the right, left, and total HGS. The percentile ranges < p15 (low), p15-p85 (normal) and $>$ p85 (high) were used. ANOVA and Kruskal-Wallis tests were applied. Results: In boys, the mean total HGS ranged from $67.5 \pm 16.5$ to $86.9 \pm 21.8(\mathrm{p}<0.001)$ and $74.3 \pm 17.5$ to $82.2 \pm 17.8(\mathrm{p}<0.001)$ for age and sexual maturation, respectively, while in girls the mean HGS total ranged from $48.8 \pm 11.3$ to $56.4 \pm 16.0(\mathrm{p}=0.127)$ and $47.8 \pm 10.6$ to $54.3 \pm 12.3$ ( $\mathrm{p}<0.001$ ). Conclusion: Reference values established by the percentile score, can be used to identify adolescents with better athletic condition and can be useful for prescribing exercises.
\end{abstract}

Keywords: adolescents, physical fitness, muscle strength dynamometer, muscle strength.

\section{Introduction}

Muscle strength has been considered an important general health indicator. This component of physical fitness can be measured in different muscle groups and through different protocols ${ }^{1}$. However, one of the forms of muscle strength manifestation, handgrip strength (HGS), measured by a handheld dynamometer, has been a recommended method for assessing muscle strength ${ }^{2}$. It is a simple and quick assessment method that, in addition to having a good relationship with other muscle strength indicators, is a good indicator of general muscle strength ${ }^{2}$.

There is a wide range of evidence pointing to low HGS as an indicator of mortality by all causes, risk of disability $^{3}$, bone fracture $^{4}$, and depression ${ }^{5}$ in different age groups. These relationships between health outcomes and muscle strength reinforce the importance of monitoring these component physical fitness levels throughout the life course ${ }^{6}$.

In general, HGS can vary according to sex and age $^{7,8}$, body dimensions ${ }^{9}$, and physical activity level ${ }^{7}$. Specifically, in adolescents, sexual maturation is an important factor that can influence muscle strength $^{10}$.
Puberty marks the transition from childhood to adulthood, a period characterized by several physical, physiological, and psychological changes ${ }^{10}$. During puberty, changes occur in growth hormones (GH and IGF-1) and sex hormones (testosterone in boys and estrogen in girls), which play an important role in varying muscle strength ${ }^{10}$.

Muscle strength in Brazilian children and adolescents has been extensively studied, using different measurement methods, however, concerning HGS, there are still few studies conducted with such a population ${ }^{11}$. One of the factors that may be related to the limited number of studies that investigated HGS may be the absence of normative values for Brazilians. In the national literature, some studies proposed normative HGS values for adults and the elderly ${ }^{12}$ and children ${ }^{13}$. Nevertheless, when it comes to adolescents, there is still no knowledge of studies dealing with this subject. As a result, studies have been restricted to using cutoff points based on adolescents from other countries ${ }^{7,14}$, which may not reflect the true Brazilian condition regarding muscle strength in this age period. For example, in a previous meta-analysis, it was reported that HGS values are substantially lower in individuals from middle-income countries when compared to high- 
income countries, possibly due to differences in body size typical of each continent ${ }^{15}$. In the case of adolescents, the puberty phase may differ according to ethnicity and geographic location ${ }^{16}$. Thus, strength development in adolescents from different countries may not occur in the same age period, preventing the general use of cutoff points proposed specifically for adolescents in any given country.

In this context, the existence of normative values of HGS in adolescents, especially considering sexual maturation, can be used as a classification criterion for adolescent HGS. These normative values can help to identify those with better or worse athletic conditions, as well as assisting physical education professionals in the prescription of physical exercises. In view of the presented gaps, the present study aimed to propose normative values of HGS, according to chronological age and sexual maturation, in adolescents from Southern Brazil.

\section{Methods}

\section{Study design and participants}

This study included data collected from adolescents aged 14 to 19 , referring to three macro projects carried out in Metropolitan Florianopolis, Santa Catarina, Brazil, in 2007,2014 , and 2017/18. The macro projects were carried out with adolescents enrolled in a high public school in Florianopolis, Santa Catarina, in 2007 (protocol n. 372/ 2006) and 2017/18 (protocol n. 2,172,699), and with adolescents enrolled in a high public school in São José (municipality of Metropolitan Florianopolis), Santa Catarina, in 2014 (protocol n. 746.536/2014).

The cities Florianópolis and São José are part of the Greater Florianópolis region, in the state of Santa Catarina and have a Municipal Human Development Index of 0.847 and 0.807 , respectively. According to the Brazilian Institute of Geography and Statistics, in 2010, Florianópolis and São José had, respectively, 421,240 and 209,804 inhabitants ${ }^{17}$. Current estimates for 2020 suggest an increase in the number of inhabitants in both Florianópolis $(\mathrm{N}=508,826)$ and São José $(\mathrm{N}=250,181)$. Between 2010 and 2018, there was an increase in PIB per capita from R\$ $26,772.55$ to $R \$ 42,719.16$ in Florianópolis, and from R\$ $24,299.00$ to $\mathrm{R} \$ 43,665.31$ in São José. In the case of the population aged 15 to 19 years old in 2010, Florianópolis had a total of 32,532 adolescents and São José of 17,186. In 2010 , the schooling rate for 6 to 14 -year-olds was $98.4 \%$ in Florianópolis and $97.5 \%$ in São José. Information on the number of adolescents and the school enrollment rate for 2020 is not available on the Institute's website.

All projects involved representative samples of the investigated population. Information on the sample parameters for the 2007 and 2014 studies can be consulted in previously published studies ${ }^{18,19}$. The procedures adopted for the 2017/18 study were the same as those used in $2007^{18}$. Following the division of the municipality into five regions, according to the Municipal Health Secretariat (Continent, North, South, East, and Center), the largest school in each region was selected. In each school, a draw was made to select the classes that would be invited to participate in the data, until the number of estimated individuals for each region was reached. As for the sample calculation, a school census for the year 2017, provided by the State Department of Education, was used, in which 10,192 adolescents were enrolled in the high public schools in Florianopolis. After performing the calculation, a minimum sample of 936 individuals was set.

\section{Eligibility criteria}

Adolescents of both sexes, aged 14 to 19 years, enrolled in selected schools, who did not have physical limitations that prevented the execution of physical tests and anthropometric measures, who were not pregnant, and who were not eligible to participate in the study informed the consent signed by the parent or guardian.

\section{Variables}

To characterize the sample, measurements of body mass and height were collected, for later calculation of the Body Mass Index (BMI), and the skinfold thickness to estimate body adiposity.

To measure body mass, a digital scale from the Plenna® brand (São Paulo, Brazil) with a resolution of $100 \mathrm{~g}$ was used. The triceps and subscapular skinfold thicknesses were measured with a scientific adipometer from the brand Cescorf (São Paulo, Brazil). In all three surveys, two trained evaluators performed two measurements (non-consecutive) for each skinfold. When there was a difference higher than $5 \%$ between the two measurements, a third one was performed. The average was used when only two measurements were performed and the median when three measurements were performed ${ }^{20}$.

BMI was calculated by the ratio of body mass in kilograms to height in meters squared. Body adiposity was estimated by the sum of two skinfolds (triceps + sub-

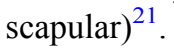

All anthropometric measurements were performed according to the protocols suggested by the International Society for the Advancement of Kinanthropometry (ISAK), with those evaluated wearing light and suitable for this type of evaluation clothing ${ }^{22}$.

HGS was measured by a Jamar® manual dynamometer (Lafayette, USA) (0.1 kg resolution). To measure the HGS, the subjects were positioned on their feet, with the upper limbs extended at the side of the body. Three alternate measurements were taken in each hand, with an interval of one minute between each measurement. Each maximum muscle contraction lasted 5 seconds. The highest measure of each hand was considered, which was then 
added up to determine the total HGS ${ }^{22}$. The HGS (right hand, left, and total hand) was also adjusted for body weight, being expressed as the normalized HGS [HGS $(\mathrm{kg})$ / body weight $(\mathrm{kg})]$. HGS is a measure that showed a strong correlation with general muscle strength in adolescents $^{23}$, in addition to having good reliability ${ }^{24}$ and reproducibility ${ }^{25}$.

Sexual maturation was determined by the growth of pubic hair according to Tanner's criteria ${ }^{26}$. In the 2007 survey, the figures proposed by Tanner ${ }^{26}$ were used, however, in the 2014 and 2017 surveys, an instrument with adapted figures ${ }^{27}$ from the Tanner instrument was used. This variable was obtained through self-report, in which the participants indicated the figure that best corresponded to their pubic hair growth. Adolescents were classified into five stages of sexual maturation. Stage 1, which corresponds to the prepubertal phase; stages 2, 3, and 4, which correspond to the pubertal phase; and stage 5, which corresponds to the postpubertal phase.

\section{Statistical analysis}

The statistical analysis was performed using the IBM SPSS Statistics 20.0 software. Descriptive statistics (averages, standard deviation, and frequencies) and inferential statistics were used. The Kolmogorov-Smirnov test was used to verify the data distribution. For mean comparisons, ANOVA and Kruskal-Wallis tests were used. To determine the normative HGS values (right hand, left hand, and total), the percentiles p3, p10, p15, p25, p50, $\mathrm{p} 75, \mathrm{p} 85, \mathrm{p} 90$, and $\mathrm{p} 97$ were calculated for each sex, according to age and sexual maturation. To establish cutoff points for different HGS levels, specific by sex, age, and sexual maturation, the percentile ranges $<$ p15 (low), p15-p85 (normal), and $>$ p85 (high), previously used by Gómez-Campos et al. ${ }^{8}$.

\section{Result}

Descriptive data for the 2,637 adolescents who participated in the study are shown in Table 1, according to age and sexual maturation stage. In boys, when comparing the averages by age, differences were observed for body weight, height, BMI, triceps skinfold, HGS of both hands, and total HGS. By stage of sexual maturation, the boys showed differences in mean height and absolute and normalized HGS for both hands and total. In girls, when compared by age, only the mean of body weight and height showed a difference. When comparing by sexual maturation stages, the absolute and normalized HGS for both hands and total demonstrated differences in girls.

Table 2 shows the percentile values of right-hand, left-hand, and total HGS for boys and girls, according to chronological age. It was observed that the HGS increased as the age of the adolescents increased, regardless of the hand (right or left) or the total strength (sum of both hands).

Table 3 shows the percentile values of the righthand, left-hand, and total HGS for boys and girls, according to the 5 stages of sexual maturation. It was verified that the HGS of both hands and total was increased in the same direction as the maturation progressed.

Based on the percentiles of the adolescents in the present study, cutoff points for total HGS were established to classify the muscle strength in adolescents (Table 4).

\section{Discussion}

This study aimed to establish normative values of HGS based on a large sample of adolescents from two cities in the coastal region of Santa Catarina. The findings add to the current literature, firstly because it proposes normative values of HGS for Brazilian adolescents, and secondly because it also considers sexual maturation, rather than just age $\mathrm{e}^{28,29}$.

When reviewing the literature, two national studies that established normative values of HGS were found, one of which was directed at children ${ }^{13}$ and the other at adults and the elderly ${ }^{12}$. Souza et al. ${ }^{13}$ conducted their study with children and adolescents aged 6 to 13 years old, from public schools in Ribeirao Preto/SP, in which HGS was measured by a bulb dynamometer. In the study by Amaral et al. ${ }^{12}$, with adults and the elderly (18 to 102 years old) from Rio Branco/AC, reference values of HGS by age groups were established by using a hydraulic manual dynamometer from Saehan SH5001. Despite these findings, studies involving adolescents were not found in the searched national literature. Thus, the results of the present study can serve as a criterion for the HGS classification of Brazilian adolescents. Besides, these results are valuable for the areas of physical activity and health and sports performance, as they can be used as a basis for the exercise prescription and to identify adolescents with good athletic conditions ${ }^{30}$. Furthermore, about the scientific environment, this study can work as a basis for future research regarding the classification of muscle strength in adolescents.

The findings of the present study corroborate studies carried out in other countries such as the United States ${ }^{28}$, Colombia $^{29}$, and Chile ${ }^{8}$, which found that HGS increased with age in adolescents, being higher in boys at all ages. Besides, the present study also analyzed the HGS values using the sexual maturation stages, noting that HGS also increased with advancing maturation in both sexes. A difference was also observed in the comparison between sexes, with higher values for boys for all stages of maturation.

The HGS analysis of children and adolescents, when considered only the chronological age may not be limited when it comes to the period in which sexual maturation 


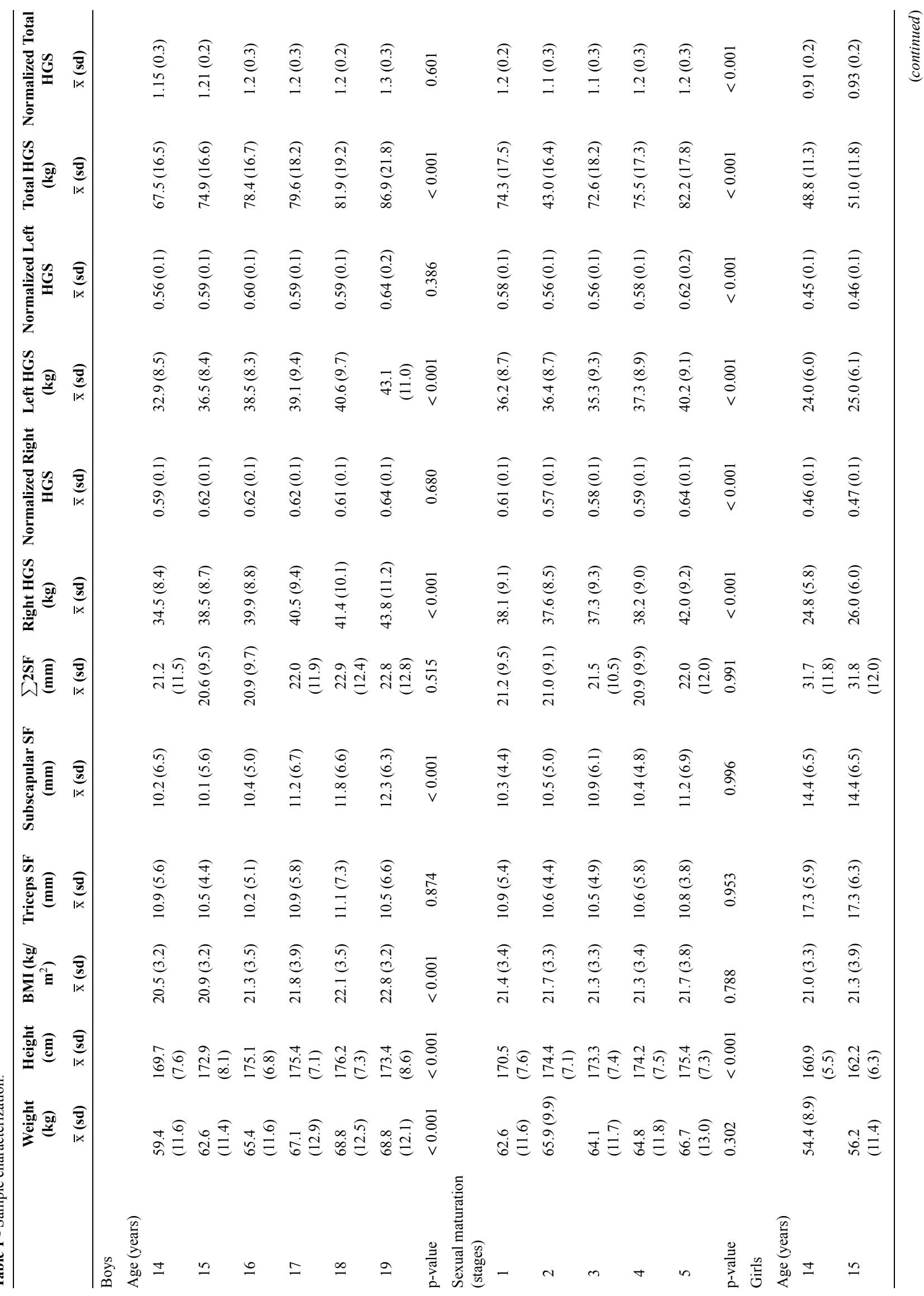




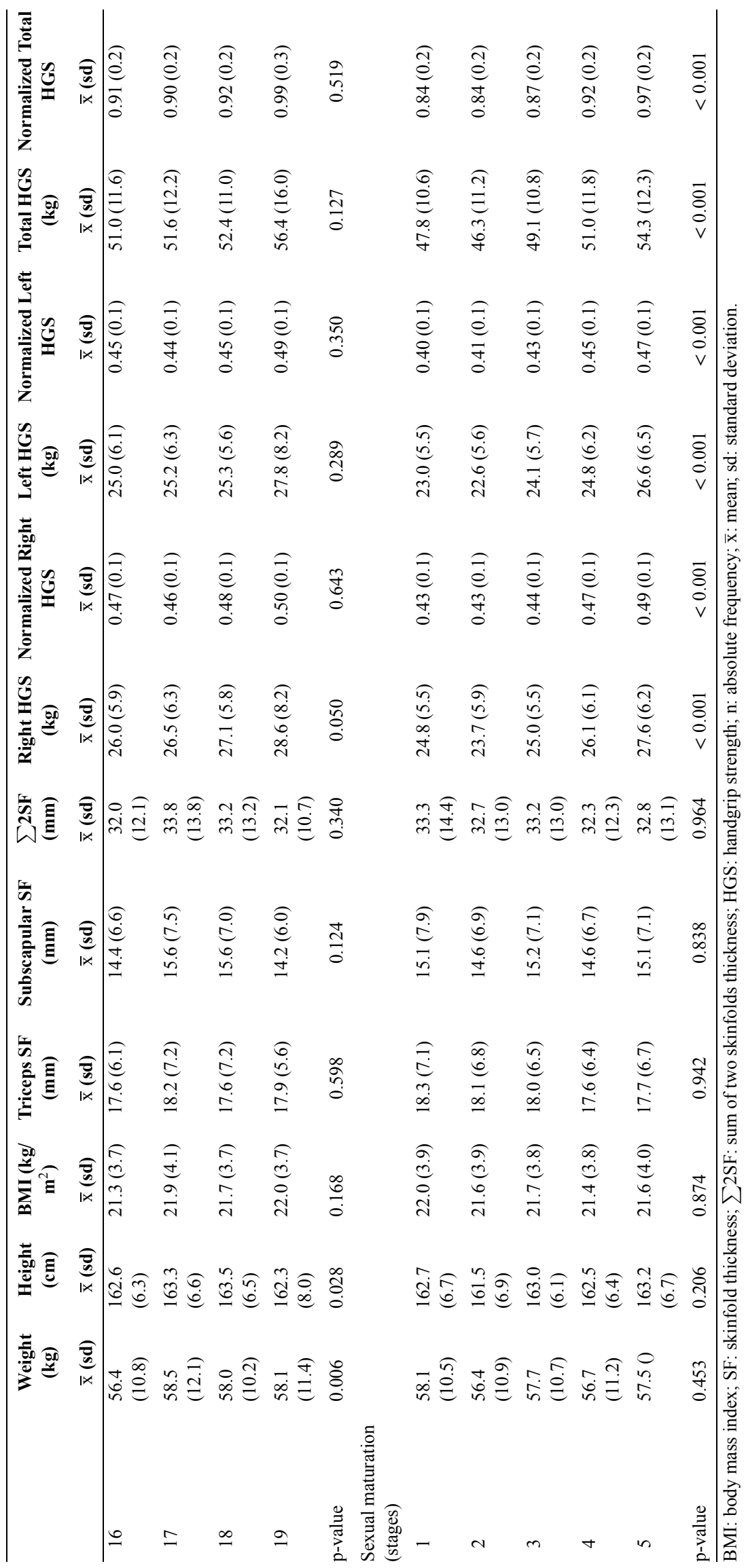


Table 2 - Normative HGS values for adolescents of both sexes, according to age.

Handgrip strength (kg)

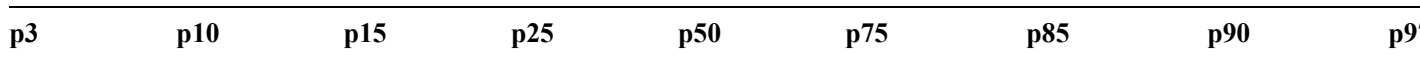

Boys

Right Hand

$14(\mathrm{n}=48)$

$\begin{array}{ll}17.5 & 22.9\end{array}$

$\begin{array}{ll}26.0 & 28.0 \\ 29.3 & 32.6 \\ 30.9 & 34.0 \\ 30.3 & 34.0 \\ 30.0 & 35.0 \\ 31.7 & 36.0\end{array}$

34.0
38.2
39.5
40.0
42.0
42.0

41.0
44.3
45.9
46.6
48.0
52.2

44.8
47.3
49.0
50.0
52.0
56.6

$\begin{array}{ll}46.2 & 50.1 \\ 50.0 & 53.6 \\ 51.5 & 58.0 \\ 54.0 & 59.5 \\ 54.3 & 60.0 \\ 58.2 & 71.6\end{array}$

\section{Left Hand}

$14(\mathrm{n}=48)$

13.8

$15(\mathrm{n}=245)$

$$
13.8
$$

22.0

24.0

27.6

\section{1}

40.5

43.8

\section{1}

47.5

$16(\mathrm{n}=344)$

$$
22.0
$$

25.9

28.0

$$
31.3
$$

41.9

44.2

46.0

54.0

$17(\mathrm{n}=377)$

21.9

28.0

30.0

33.6

38.0

43.0

47.2

49.0

54.7

$18(\mathrm{n}=157)$

21.5

28.9

33.9

48.0

51.1

53.7

58.1

$19(\mathrm{n}=38)$

22.6

26.0

28.9

33.9

40.5

48.0

51.1

53.7

58.1

Total

$14(\mathrm{n}=48)$

31.3

\section{7}

48.7

55.8

50.4

54.4

57.1

69.1

$15(\mathrm{n}=245)$

40.8

52.3

56.0

64.3

66.0

79.6

88.3

89.3

96.1

$16(\mathrm{n}=344)$

46.0

58.1

62.0

68.0

86.0

92.0

94.8

107.2

$17(\mathrm{n}=377)$

48.3

61.0

66.7

77.2

88.2

95.9

99.8

112.0

$18(\mathrm{n}=157)$

44.3

55.0

59.7

70.5

$19(\mathrm{n}=38)$

48.0

53.3

63.2

71.0

78.3

91.0

98.0

104.0

116.8

96.5

101.6

106.8

118.5

104.9

108.3

112.6

140.8

Right Hand

$14(\mathrm{n}=57)$

$15(\mathrm{n}=335)$

$$
10.4
$$

18.0

20.0

\section{0}

20.0

$$
22.0
$$

24.0

28.0

32.0

32.2

38.5

$16(\mathrm{n}=450)$

15.0

18.3

20.0

22.0

26.0

30.0

32.0

34.0

38.0

$17(\mathrm{n}=443)$

18.0

20.0

22.0

30.0

32.0

34.0

38.0

$18(\mathrm{n}=106)$

16.0

18.9

20.3

23.2

26.0

30.0

32.7

34.0

39.7

$19(\mathrm{n}=37)$

16.2

19.3

20.7

22.5

28.0

31.3

33.0

34.3

38.0

Left Hand

$14(\mathrm{n}=57)$

$$
11.0
$$

15.6

18.7

$20.4 \quad 24.0$

32.0

36.6

38.2

57.2

$15(\mathrm{n}=335)$

14.0

17.0

19.0

20.4

24.0

28.0

29.1

$$
30.0
$$

31.9

33.5

38.1

$16(\mathrm{n}=450)$

13.2

18.0

19.0

20.4

25.0

29.0

31.8

$$
33.0
$$

33.5

$$
32.0
$$

38.4

36.0

$19(\mathrm{n}=37)$

16.0

17.0

19.6

20.5

25.0

29.9

31.0

$\begin{array}{llll}38.0 & 42.0 & 48.0 & 56.5\end{array}$

$21.7 \quad 36.0$

38.5

\section{6}

39.0

42.5

50.4

58.0

60.0

$62.6 \quad 74.5$

$16(\mathrm{n}=450)$

31.0

39.8

43.0

50.0

58.0

63.9

$\begin{array}{ll}66.0 & 75.8\end{array}$

$17(\mathrm{n}=443)$

30.0

36.0

40.1

43.9

51.2

59.6

62.5

$66.0 \quad 74.5$

$18(\mathrm{n}=106)$

32.0

38.0

39.0

46.0

52.0

60.3

64.0

$\begin{array}{ll}67.0 & 76.5\end{array}$

54.5

64.1

64.0

67.9

74.0

\begin{tabular}{lll}
70.6 & 74.4 & 111.2 \\
\hline
\end{tabular}


Table 3 - Normative HGS values for adolescents of both sexes, according to sexual maturation stage.

\begin{tabular}{|c|c|c|c|c|c|c|c|c|c|}
\hline & & & & & rip str & & & & \\
\hline & p3 & p10 & p15 & p25 & p50 & p75 & p85 & p90 & p97 \\
\hline Boys & & & & & & & & & \\
\hline Right Hand & & & & & & & & & \\
\hline Stage $1(n=32)$ & 18.0 & 24.4 & 30.0 & 31.8 & 38.0 & 45.5 & 49.1 & 50.0 & - \\
\hline Stage $2(n=36)$ & 20.4 & 25.4 & 28.0 & 30.5 & 38.0 & 42.9 & 48.7 & 50.0 & 54.3 \\
\hline Stage $3(n=91)$ & 21.2 & 24.3 & 28.0 & 31.0 & 36.7 & 42.6 & 46.3 & 51.6 & 58.3 \\
\hline Stage $4(n=468)$ & 22.0 & 26.0 & 28.0 & 32.0 & 38.0 & 44.0 & 48.0 & 50.0 & 56.0 \\
\hline Stage $5(\mathrm{n}=582)$ & 25.3 & 30.5 & 32.5 & 36.0 & 42.0 & 47.7 & 51.0 & 54.0 & 60.0 \\
\hline Left Hand & & & & & & & & & \\
\hline Stage $1(n=32)$ & 17.0 & 22.3 & 27.8 & 30.0 & 37.2 & 43.0 & 45.2 & 49.4 & - \\
\hline Stage $2(n=36)$ & 20.0 & 21.7 & 23.6 & 31.0 & 38.0 & 42.0 & 44.0 & 47.3 & 51.7 \\
\hline Stage $3(n=91)$ & 16.9 & 24.0 & 25.8 & 29.4 & 35.3 & 40.3 & 43.3 & 47.8 & 56.3 \\
\hline Stage $4(n=468)$ & 20.0 & 25.8 & 28.0 & 32.0 & 37.0 & 43.0 & 46.0 & 48.0 & 56.0 \\
\hline Stage $5(\mathrm{n}=582)$ & 23.8 & 29.0 & 31.0 & 34.0 & 40.0 & 46.0 & 496 & 52.0 & 58.2 \\
\hline Total & & & & & & & & & \\
\hline Stage $1(n=32)$ & 35.0 & 45.7 & 57.7 & 61.8 & 75.8 & 88.8 & 94.1 & 97.4 & - \\
\hline Stage $2(n=36)$ & 42.3 & 46.7 & 52.2 & 63.3 & 76.0 & 82.0 & 90.5 & 94.3 & 106.0 \\
\hline Stage $3(n=91)$ & 39.0 & 50.4 & 53.3 & 60.0 & 71.4 & 83.2 & 89.8 & 99.7 & 111.2 \\
\hline Stage $4(n=468)$ & 43.2 & 52.7 & 57.1 & 63.4 & 75.1 & 87.0 & 93.8 & 98.0 & 111.3 \\
\hline Stage $5(n=582)$ & 49.3 & 60.8 & 64.0 & 70.0 & 82.0 & 93.2 & 100.0 & 106.0 & 117.9 \\
\hline Girls & & & & & & & & & \\
\hline Right Hand & & & & & & & & & \\
\hline Stage $1(n=36)$ & 9.9 & 18.0 & 18.9 & 20.5 & 25.0 & 29.4 & 30.3 & 31.3 & 35.7 \\
\hline Stage $2(n=71)$ & 15.0 & 17.0 & 18.0 & 20.0 & 22.5 & 27.4 & 29.6 & 31.8 & 38.5 \\
\hline Stage $3(n=210)$ & 16.0 & 18.3 & 19.7 & 21.7 & 24.0 & 28.4 & 31.0 & 32.4 & 36.6 \\
\hline Stage $4(n=702)$ & 15.0 & 18.0 & 20.0 & 22.0 & 26.0 & 30.0 & 32.0 & 34.0 & 38.0 \\
\hline Stage $5(n=409)$ & 17.3 & 20.0 & 22.0 & 23.1 & 27.7 & 31.9 & 34.1 & 36.0 & 40.0 \\
\hline Left Hand & & & & & & & & & \\
\hline Stage $1(n=36)$ & 10.9 & 14.0 & 16.6 & 19.0 & 24.2 & 27.8 & 28.0 & 30.3 & 31.9 \\
\hline Stage $2(n=71)$ & 14.0 & 16.0 & 16.8 & 19.0 & 21.0 & 26.0 & 30.0 & 30.4 & 34.0 \\
\hline Stage $3(n=210)$ & 14.3 & 17.0 & 18.0 & 20.0 & 23.9 & 28.0 & 30.8 & 32.0 & 35.0 \\
\hline Stage $4(n=702)$ & 14.0 & 17.7 & 19.0 & 20.8 & 24.4 & 29.0 & 31.0 & 32.1 & 37.9 \\
\hline Stage $5(n=409)$ & 15.0 & 18.0 & 20.0 & 22.0 & 26.5 & 30.0 & 33.3 & 35.1 & 39.7 \\
\hline Total & & & & & & & & & \\
\hline Stage $1(n=36)$ & 21.1 & 35.7 & 36.0 & 38.3 & 50.5 & 55.8 & 58.5 & 61.9 & 65.8 \\
\hline Stage $2(n=71)$ & 30.3 & 33.2 & 35.0 & 39.0 & 44.2 & 52.5 & 56.4 & 62.9 & 71.9 \\
\hline Stage $3(n=210)$ & 32.0 & 36.6 & 38.0 & 41.0 & 48.0 & 56.2 & 62.0 & 64.0 & 71.9 \\
\hline Stage $4(n=702)$ & 29.1 & 36.0 & 39.5 & 43.0 & 51.0 & 58.0 & 63.0 & 66.0 & 74.0 \\
\hline Stage $5(n=409)$ & 32.9 & 38.5 & 40.9 & 45.9 & 54.0 & 61.4 & 68.0 & 70.8 & 78.1 \\
\hline
\end{tabular}

occurs, as reported by Gómez-Campos et al. ${ }^{8}$. The authors observed differences when determining HGS according to chronological age and biological age for children and adolescents between six and 17.9 years. In this study, it was observed that for chronological age, there are no differences between sexes for six to 12 years, with a higher HGS in boys of subsequent ages. When analyzing by bio- logical age (determined by the peak height velocity), higher values of HGS were found for boys at all levels of the peak height velocity. Furthermore, the study revealed that when using biological age, HGS was higher in 5\% of boys and $5 \%$ of girls ${ }^{8}$. This indicates that maturational aspects can better discriminate the HGS level when compared to chronological age. These differences exist due to 
Table 4 - Cutoff points for total HGS, based on the participants in the present study.

\begin{tabular}{|c|c|c|c|c|c|c|}
\hline & \multicolumn{6}{|c|}{ Cutoff points for total HGS (kg) } \\
\hline & \multicolumn{3}{|c|}{ Boys } & \multicolumn{3}{|c|}{ Girls } \\
\hline & Low $(<$ p15) & Normal (p15-p85) & High $(>$ p85) & Low $(<p 15)$ & Normal (p15-p85) & High $(>$ p85) \\
\hline \multicolumn{7}{|l|}{ Age } \\
\hline 14 & $\leq 48.6$ & $48.7-88.3$ & $\geq 88.4$ & $\leq 37.9$ & $38.0-60.0$ & $\geq 60.1$ \\
\hline 15 & $\leq 55.9$ & $56.0-92.0$ & $\geq 92.1$ & $\leq 38.4$ & $38.5-63.9$ & $\geq 64.0$ \\
\hline 16 & $\leq 61.9$ & $62.0-95.9$ & $\geq 96.0$ & $\leq 38.9$ & $39.0-62.5$ & $\geq 62.6$ \\
\hline 17 & $\leq 60.9$ & $61.0-98.0$ & $\geq 98.1$ & $\leq 39.7$ & $39.8-64.0$ & $\geq 64.1$ \\
\hline 18 & $\leq 59.8$ & $59.7-101.6$ & $\geq 101.7$ & $\leq 40.0$ & $40.1-64.0$ & $\geq 64.1$ \\
\hline 19 & $\leq 63.1$ & $63.2-108.3$ & $\geq 108.4$ & $\leq 38.9$ & $39.0-70.6$ & $\geq 70.7$ \\
\hline \multicolumn{7}{|c|}{ Sexual maturation } \\
\hline Stage 1 & $\leq 57.6$ & $57.7-94.1$ & $\geq 94.2$ & $\leq 35.9$ & $36.0-58.5$ & $\geq 58.6$ \\
\hline Stage 2 & $\leq 52.1$ & $52.2-90.5$ & $\geq 90.6$ & $\leq 34.9$ & $35.0-56.4$ & $\geq 56.5$ \\
\hline Stage 3 & $\leq 53.2$ & $53.3-89.8$ & $\geq 89.9$ & $\leq 37.9$ & $38.0-62.0$ & $\geq 62.1$ \\
\hline Stage 4 & $\leq 57.0$ & $57.1-93.8$ & $\geq 93.9$ & $\leq 39.4$ & $39.5-63.0$ & $\geq 63.1$ \\
\hline Stage 5 & $\leq 63.9$ & $64.0-100.0$ & $\geq 100.1$ & $\leq 40.8$ & $40.9-68.0$ & $\geq 68.1$ \\
\hline
\end{tabular}

${ }^{*}$ Percentile ranges used in a previous study ${ }^{8}$.

the beginning, length, and intensity of the pubescent process, which occurs at different ages for each individual ${ }^{31}$.

During sexual maturation, significant changes occur in hormonal, physical and, psychosocial aspects ${ }^{31}$. Regarding physical and hormonal changes, these differ in intensity between sexes and may manifest earlier in girls $^{31}$. As an example, greater increases in HGS were observed in girls aged nine to 11 years old, while in boys the higher increase occurred from 13 to 14 years old ${ }^{32}$. With puberty, there is an increase in sex hormones ${ }^{10}$, which influence muscle strength gain. With the boys, there is an increase in the concentration of the testosterone hormone, which is related to an increase in lean mass, reduction of adipose tissue, and increase in muscle strength ${ }^{30}$. In girls, with the advancement of sexual maturation, the concentration of the hormone estradiol increases, which is related to better performance in muscle strength ${ }^{33}$.

Some limitations must be considered in the present study. One is the lack of information about the dominant hand of the investigated adolescents. Besides, the absence of socioeconomic information and the practice of physical activities limit a better characterization of the sample.

The study's strength is to establish the normative values of HGS according to sexual maturation, unlike the way that most of the literature has worked. This stratification sought to overcome some limitations that age control could imply since the sexual maturation process (which influences muscle strength gain) can start at different ages and have different durations and intensities for each individual. Moreover, the study was conducted with a large sample of adolescents from the Metropolitan Florianopolis region, in Santa Catarina, Brazil.

\section{Conclusion}

It was concluded that there was an increase in HGS according to the advancement in sexual maturation and age, with higher values for boys compared to girls. The normative values of HGS for boys and girls were established, according to age and sexual maturation, in addition to suggesting cutoff points for different HGS levels. The established reference values, through the percentile score, can serve as a criterion for classifying muscle strength, in identifying adolescents with better athletic condition and can be useful for prescribing physical exercises. It is suggested that future studies seek to establish normative values of HGS according to the sexual maturation, in samples with a broader age range, covering the entire adolescence phase (for example 10 to 19 years old). Furthermore, future studies can verify the accuracy of HGS in predicting other health outcomes, such as the risk of cardiovascular and metabolic diseases.

\section{Acknowledgments}

This work was supported by the Fundação de Amparo à Pesquisa e Inovação do Estado de Santa Catarina (FAPESC) [grant number 2019TR784].

\section{References}

1. Benfica PA, Aguiar LT, Brito SAF, Bernardino LHN, Teixeira-Salmela LF, Faria CDCM. Reference values for muscle strength: a systematic review with a descriptive metaanalysis. Braz J Phys Ther. 2018;22(5):355-69. doi: https:// doi.org/10.1016/j.bjpt.2018.02.006 
2. Bohannon RW. Muscle strength: clinical and prognostic value of hand-grip dynamometry. Curr Opin Clin Nutr Metab Care. 2015;18(5):465-70. doi: https://doi.org/ 10.1097/MCO.0000000000000202

3. Soysal P, Hurst C, Demurtas J, Firth J, Howden R, Yang L et al. Handgrip strength and health outcomes: Umbrella review of systematic reviews with meta-analyses of observational studies. J Sport Health Sci. 2021;10:290-5 doi: https://doi.org/10.1016/j.jshs.2020.06.009

4. Cheung CL, Tan KC, Bow CH, Soong CS, Loong CH, Kung AWC. Low handgrip strength is a predictor of osteoporotic fractures: cross-sectional and prospective evidence from the Hong Kong Osteoporosis Study. Age. 2012;34(5):1239-48. doi: https://doi.org/10.1007/s11357-011-9297-2

5. Marques A, Gomez-Baya D, Peralta M, Frasquilho D, Santos T, Martins J, et al. The effect of muscular strength on depression symptoms in adults: a systematic review and meta-analysis. Int J Environ Res Public Health. 2020;17 (16):5674. doi: https://doi.org/ 10.3390/ijerph17165674

6. Fraser BJ, Schmidt MD, Huynh QL, Dwyer T, Venn AJ, Magnussen CG. Tracking of muscular strength and power from youth to young adulthood: Longitudinal findings from the Childhood Determinants of Adult Health Study. J Sci Med Sport. 2017;20(10):927-31. https://doi.org/10.1016/j. jsams.2017.03.021

7. Silva DAS, Pelegrini A, Castro JAC, Lima TR, Sousa GR, Silva JMFL, et al. Low handgrip strength levels among adolescents in a city in southern Brazil. J Body Mov Ther. 2017;21(4):884-9. doi: https://doi.org/10.1016/j. jbmt.2017.03.004

8. Gómez-Campos R, Andruske CL, Arruda MD, Sulla-Torres J, Pacheco-Carrillo J, Urra-Albornoz C, et al. Normative data for handgrip strength in children and adolescents in the Maule Region, Chile: Evaluation based on chronological and biological age. PLoS One. 2018;13(8):e0201033. doi: https://doi.org/10.1371/journal.pone.0201033

9. Musa TH, Li W, Xiaoshan L, Guo Y, Wenjuan Y, Xuan Y, et al. Association of normative values of grip strength with anthropometric variables among students, in Jiangsu Province. Homo. 2018;69(1-2):70-6. doi: https://doi.org/ 10.1016/j.jchb.2018.03.0077

10. Goswami B, Roy AS, Dalui R, Bandyopadhyay A. Impact of pubertal growth on physical fitness. Am J Sport Sci Med. 2014;2(5A):34-9. doi: https://doi.org/ 10.12691/ajssm-2$5 \mathrm{~A}-8$

11. Lima TRD, Moraes MS, Martins PC, Silva VSD, Silva DAS. Diversity of parameters in the muscle strength evaluation of Brazilian school children and adolescents: a systematic review. Rev Bras Cineantropom Desempenho Hum. 2018;20(4):497-516. doi: https://doi.org/10.1590/1980$0037.2018 v 20 n 4 p 497$

12. Amaral CA, Amaral TLM, Monteiro GTR, Vasconcellos MTL, Portela MC. Handgrip strength: Reference values for adults and elderly people of Rio Branco, Acre, Brazil. PLoS One. 2019;14(1):e0211452. doi: 10.1371/journal. pone. 0211452

13. Souza MA, Benedicto MMB, Pizzato TM, Mattiello-Sverzut AC. Normative data for handgrip strength in healthy children measured with a bulb dynamometer: a cross-sec- tional study. Physiotherapy. 2014;100(4):313-18. doi: https://doi.org/10.1016/j.physio.2013.11.004

14. Lima TRD, Sousa GR, Castro JAC, Silva DAS. Prevalência de baixos níveis de força muscular e fatores associados em adolescentes de uma cidade do sul do Brasil. Revista Bras Educ Fís Esporte. 2019;33(1):115-126. doi: https:/doi.org/ 10.11606/issn.1981-4690.v33i1p115-126

15. Dodds RM, Syddall HE, Cooper R, Kuh D, Cooper C, Sayer AA. Global variation in grip strength: a systematic review and meta-analysis of normative data. Age Ageing. 2016;45 (2):209-16. doi: https://doi.org/10.1093/ageing/afv192

16. Eckert-Lind C, Busch AS, Petersen JH, Biro FM, Butler G, Bräuner EV, et al. Worldwide secular trends in age at pubertal onset assessed by breast development among girls: a systematic review and meta-analysis. JAMA Pediatr. 2020;174(4):e195881. doi: https://doi.org/10.1001/jamapediatrics.2019.5881

17. Instituto Brasileiro de Geografia e Estatística. Cidades. IBGE. Available from: https://cidades.ibge.gov.br/ [Accessed 19th April 2021].

18. Pelegrini A, Pinto AA, Petroski EL. Agreement between body mass index and the sum of skinfolds in adolescents with different levels of physical activity. Human Movement. 2018;19(2):11-17. doi: https://doi.org/10.5114/ $\mathrm{hm} .2018 .74056$

19. Gonzaga I, Claumann GS, Scarabelot KS, Silva DAS, Pelegrini A. Body image dissatisfaction in adolescents: Comparison with physical activity, teasing and social support. J Health Psychol. 2019;11. doi: https://doi.org/10.1177/ 1359105319887796

20. Costa RF. Composição corporal: teoria e prática da avaliação. Ed. Barueri, Manole, 2001.

21. Lohman TG. The use of skinfold to estimate body fatness in children and youth. J Phys Educ Recreat Dance. 1987;58 (1):98-102

22. Canadian Society for Exercise Physiology. The Canadian Physical Activity, Fitness \& Lifestyle Appraisal: CSEP's Plan for Healthy Living. 3rd ed. Ottawa, Ontario, Canada, Canadian Society for Exercise Physiology, 2004.

23. Wind AE, Takken T, Helders PJ, Engelbert RH. Is grip strength a predictor for total muscle strength in healthy children, adolescents, and young adults? Eur J Pediatr. 2010;169(3):281-7. https://doi.org/10.1007/s00431-009$1010-4$

24. Ortega FB, Artero EG, Ruiz JR, Vicente-Rodriguez G, Bergman P, Hagströmer M, et al. Reliability of health-related physical fitness tests in European adolescents. The HELENA Study. Int $J$ Obes. 2008;32(5):S49-S57. https:// doi.org/10.1038/ijo.2008.183

25. Garcia-Hermoso A, Cofre-Bolados C, Andrade-Schnettler $\mathrm{R}$, Ceballos-Ceballos R, Fernández-Vergara O, Vegas-Heredia ED, et al. Normative reference values for handgrip strength in Chilean children at 8-12 years old using the empirical distribution and the lambda, mu, and sigma statistical methods. J Strength Cond Res 2018;35(1):260-6. https://doi.org/10.1519/JSC.0000000000002631

26. Tanner JM. Growth at adolescence. Ed. Oxford, Blackwell Scientific, 1962. 
27. Adami F, Vasconcelos FAG. Obesidade e maturação sexual precoce em escolares de Florianópolis-SC. Rev Bras Epidemiol. 2008;11:549-60. doi: https://doi.org/10.1590/S1415790X2008000400004

28. Bohannon RW, Wang YC, Bubela D, Gershon RC. Handgrip strength: a population-based study of norms and age trajectories for 3-to 17-year-olds. Pediatr Phys Ther. 2017;29(2):118-23. doi: https://doi.org/10.1097/PEP.0000000000000366

29. Ramírez-Vélez R, Morales O, Peña-Ibagon JC, PalaciosLópez A, Prieto-Benavides DH, Vivas A, et al. Normative reference values for handgrip strength in Colombian schoolchildren: the FUPRECOL study. J Strength Cond Res. 2017;31(1):217-26. doi: https://doi.org/10.1519/JSC.0000000000001459

30. Almeida-Neto PFD, Matos DG, Pinto VCM, Dantas PMS, Cesário TDM, Silva LF, et al. Can the neuromuscular performance of young athletes be influenced by hormone levels and different stages of puberty? Int J Environ Res Public Health. 2020;17(16):5637. doi: https://doi.org/10.3390/ ijerph17165637

31. Alsaker FD, Flammer A. Pubertal maturation. In: Handbook of adolescent development. Ed. Psychology Press, 2020.

32. Serrano MM, Collazos JR, Romero SM, Santurino MM, Armesilla MC, Cerro JP, et al. Dinamometría en niños y jóvenes de entre 6 y 18 años: valores de referencia, asocia- ción con tamaño y composición corporal. Anales de Pediatría. 2009;70(4):340-8. doi: https://doi.org/ 10.1016/j. anpedi.2008.11.025

33. Almeida-Neto PF, Dantas PMS, Pinto VCM, Cesário TDM, Campos N. MR., Santana E, et al. Biological maturation and hormonal markers, relationship to Neuromotor performance in female children. Int $\mathbf{J}$ Environ Research Public Health. 2020;17(9):3277. doi: https://doi.org/10.3390/ ijerph 17093277

\section{Corresponding author}

Andreia Pelegrini. Universidade do Estado de Santa Catarina, Coqueiros, Florianópolis, SC, Brasil.

E-mail: andreia.pelegrini@udesc.br.

Manuscript received on April 26, 2021

Manuscript accepted on May 27, 2021

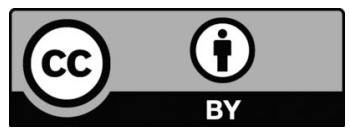

Motriz. The Journal of Physical Education. UNESP. Rio Claro, SP, Brazil - eISSN: 1980-6574 - under a license Creative Commons - Version 4.0 